Submitted to Current Opinion in Solid State and Materials Science, 2015, revised April

19, 2016

\title{
Shape Memory Strains and Temperatures in the Extreme
}

\author{
H. Sehitoglu*, L.Patriarca, Y.Wu \\ ${ }^{1}$ Department of Mechanical Science and Engineering, University of Illinois at Urbana- \\ Champaign, 1206 W. Green Street, Urbana, IL 61801, USA, \\ * Corresponding Author: huseyin@illinois.edu
}

\begin{abstract}
It is well known that the achievement of high transformation strains in shape memory alloys (SMAs) has been curtailed by plastic deformation mediated via dislocation slip. In particular, the utilization of SMAs at high temperatures is also hindered by plastic slip. In this paper, an overview of the most important SMAs is provided by constructing transformation strain, transformation temperature, and slip resistance plots to put existing works in perspective. To this plots, we added results on NiTiHf alloys which impart both high temperature capability and high slip resistance at unprecedented levels. The remarkable finding is that NiTiHf alloys can undergo transformation strains near $20 \%$ and transformation temperatures exceeding $400^{\circ} \mathrm{C}$.
\end{abstract}

\section{Introduction}

The SMAs have been the subject of intense scientific curiosity since their discovery more than 50 years ago. Several books have been written which have covered the state of art in the 1980s through the 2000s [1-5]. Many ongoing symposia on martensitic phase transformations, such as ICOMAT (International Conference on Martensitic Transformations) and ESOMAT (European Symposium on Martensitic Transformations), are now focused heavily on SMA centric research. A new journal exclusively on SMA, under the aegis of American Society of Metals International and Shape Memory and Superelastic Technologies (SMST), was launched last year [5]. The quest to reach higher transformation temperatures while not compromising slip resistance is ongoing, as evidenced from special symposia on the topic of high temperature SMAs (HTSMAs) and many recent works. There are also advantages in extending the 
transformation recoverability to high strains to improve fatigue and fracture resistance. Despite these intense activities in SMA research, the success in raising the transformation strain, transformation temperatures and slip resistance, beyond $12 \%, 250^{\circ} \mathrm{C}$ and $1 \mathrm{GPa}$ respectively, has remained elusive. In this paper we provide an overview of the current SMAs and discuss their high temperature, high strain capabilities and flow resistance, before presenting results on the NiTiHf system. We then outline conclusions and future directions.

It is instructive to define the unique behavior of SMAs with the aid of Figure 1. The 'transformation strain', the 'slip resistance' and the 'transformation temperature' parameters are all marked in Figure 1. The transformation strain can be obtained from three types of experiments: strain recovery upon heating (called shape memory effect $(\mathrm{SME})$ ), strain recovery upon unloading (called superelasticity (SE)), and the strain recoverability upon heating and cooling under isobaric conditions (ISME). The 'transformation strain' is marked for ISME case in the schematic in Figure 1. The transformation strain results for all three cases should agree, in principle. At low temperatures, martensite twinning occurs and deformation is recovered upon heating (SME). The martensite 'twinning stress' is marked in Figure 1. In the stress induced transformation region, the 'transformation stress' increases with increasing temperature and superelastic response (SE) is observed above the austenite finish temperature. The austenite finish temperature is designated as the 'transformation temperature' in Figure 1. At high temperature, the 'slip stress of austenite' decreases with increasing temperature. The slip resistance corresponds to the critical stress level at the $M_{d}$ temperature. The $M_{d}$ temperature is the highest temperature above which martensite can no longer be stressinduced. Above $\mathrm{M}_{\mathrm{d}}$, the material flows via plastic deformation. The dislocation flow stress of austenite (above $\mathrm{A}_{\mathrm{f}}$ ) is important, because during the transformation processes the austenite slip at the $\mathrm{A} / \mathrm{M}$ interfaces, and in adjacent matrix domains, can render the process irreversible at the micro-scale. 


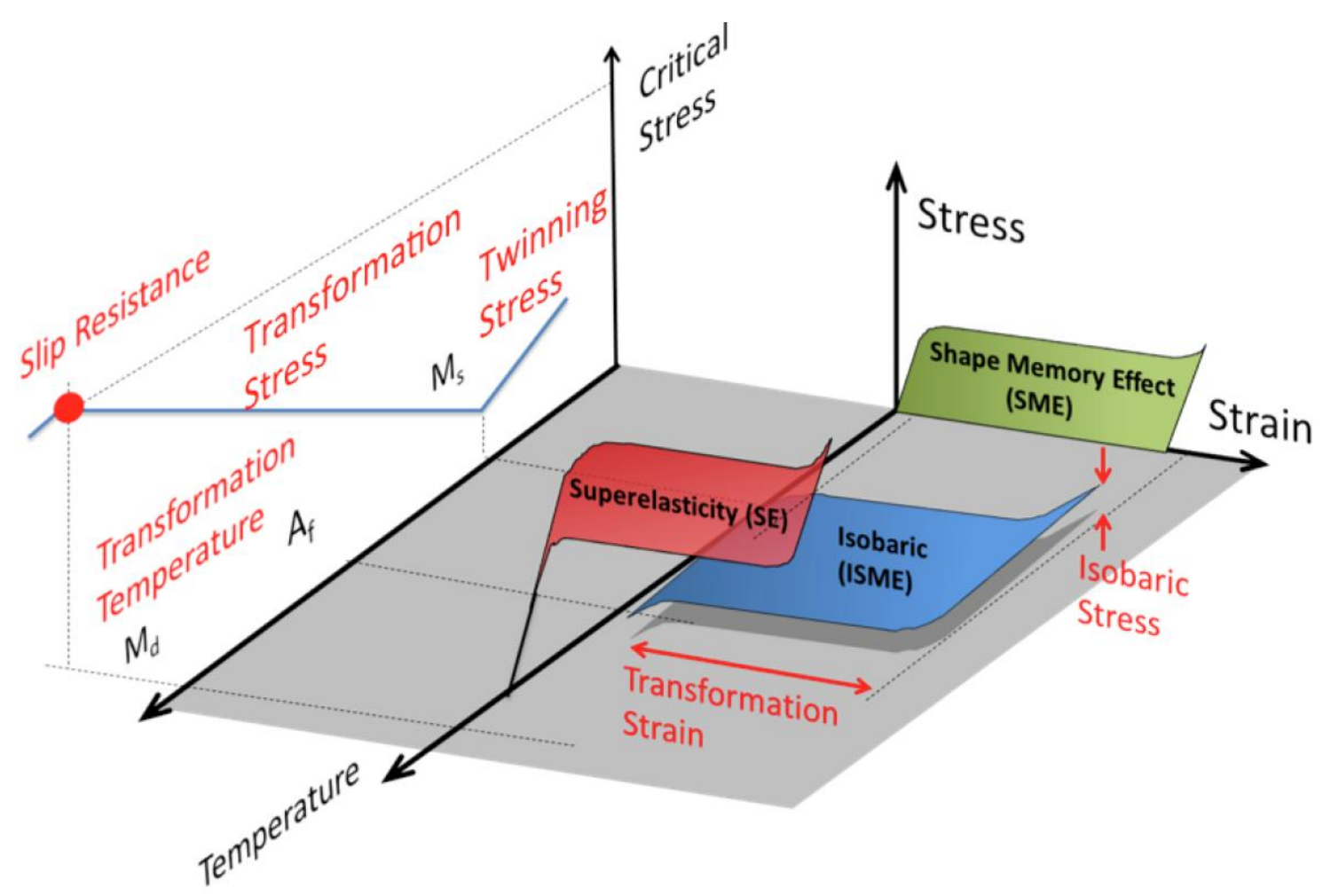

Figure 1. The demonstration of the three key parameters in Shape Memory Alloys that are highlighted in this study. The 'Slip Resistance' is defined as the flow stress of austenite, the 'Transformation Temperature' is defined as austenite finish temperature, and the 'Transformation Strain' is obtained from one of three type of experiments SME=Shape memory effect, SE=Superelasticity, and ISME-Isobaric Shape Memory Effect.

Early emphasis in SMAs focused on experimentation with copper based alloys $[4,6]$ that show excellent transformation strains but poor plastic deformation resistance [7-9]. They are no longer pursued vigorously because of their weak fatigue response and dislocation slip-induced irreversibility [7, 8, 10,11]. The discovery of NiTi with its remarkable properties has revolutionized the SMA research field [12]. Not only does the NiTi exhibit good transformation strains, it has excellent plastic slip resistance imparting stable response over many cycles [13, 14]. The NiTi alloys have a maximum transformation strain of $10 \%$ and this has been viewed as a ceiling $[15,16]$. There are advantages in developing SMAs that give higher transformation strains because this will 
result in higher damage tolerance and better functional properties for applications. We also note that the use of NiTi is limited to less than $75^{\circ} \mathrm{C}$ [17]. At elevated temperatures, the activation of slip and diffusional effects impedes the reversibility of transformation [18]. The development of higher temperature SMAs (HTSMAs) continues to remain challenging. Ideally, higher transformation temperatures (near $400^{\circ} \mathrm{C}$ ) could open significant applications in various industries. In this regard, the NiTiHf alloys permit high maximum strain, high transformation temperature and possess excellent slip resistance and is the topic of this paper.

\subsection{Transformation Strain-Slip Resistance Behavior of SMAs}

In Figure 2, we provide a combined transformation strain - slip resistance plot. The most important observation that stands out in Figure 2 is the ultra-high strains for the case of NiTiHf ( $\sim 50.3 \%$ at.Ni, $13.3 \%$ or $25 \%$ at. Hf, Ti balance, designated as $\mathrm{NiTiHf}_{13.3}$ and $\mathrm{NiTiHf}_{25}$ respectively) in tension which we expound in the next section. We assert that the slip resistance of the B2 NiTiHf alloys exceeds other SMA materials. For $\mathrm{NiTiHf}_{13.3}$ and $\mathrm{NiTiHf}_{25}$, we indicate the tension and compression levels (tension versus compression denoted by $-\mathrm{T}$ versus $-\mathrm{C}$ respectively), as well as the potential range of slip resistance associated with thermo-mechanical treatments. The difference in tension and compression is primarily attributed to the transformation planes having low symmetry indices, i.e. the habit plane system [19]. The difference between $\mathrm{NiTiHf}_{13.3}$ and $\mathrm{NiTiHf}_{25}$ transformation strains is the increased volume fraction of precipitates and the increased presence of the orthorhombic martensite domains with increasing Hf contents. 


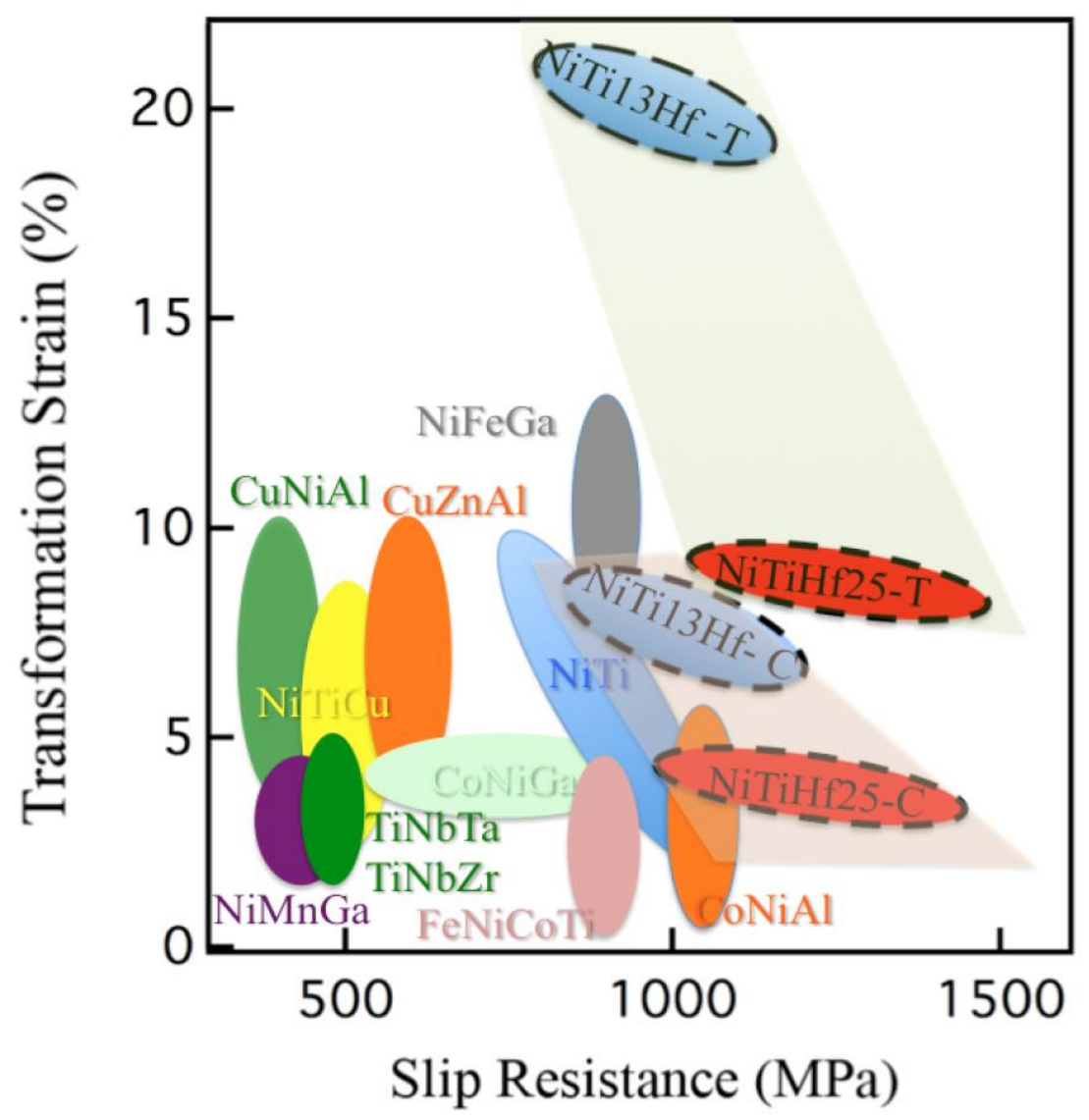

Figure 2. Transformation Strain-Slip Resistance plot showing the most well-known SMAs in comparison with the NiTiHf alloys. The tension results are separated from the compression results by shading with a different color.

Most ordered SMAs, such as B2, exhibit strong plastic flow resistance [20]; the disordered alloys, such as fcc or bcc crystal structures, have weaker slip resistance but can be strengthened via precipitation hardening (upon aging) or ordering treatments [2124]. The precipitates can be used to tailor transformation temperatures [25], reduce hysteresis [26, 27], adjust the transformation stress [17] which are all beneficial. They do reduce the transformation strains to a smaller degree [28], the benefits out weigh the decrease in transformation strains. The transformation strain also depends on the composition of the alloys. Even small changes in the alloy content in NiTi are known to have dramatic effect on the results. This sensitivity to composition exists with other alloys as well. As stated above, the strain levels in most SMAs are below 10\%. The alloys that have been of considerable focus in early works include the $\mathrm{Cu}$ based SMAs 
with seemingly excellent functionality suffer from poor plastic deformation resistance. The NiFeGa and $\mathrm{CoNiAl}(\mathrm{Ga})$ alloys stand out as potentially very good candidates as they exhibit both favorable strains and slip resistance [29-31]. Their transformation strains are in the range 6 to $12 \%$ for cubic to tetragonal transformation. Their transformation behavior is highly orientation dependent and they need heavy texturing which precludes their widespread application. The NiMnGa alloys are brittle in tension and they can only be used in compression; nonetheless they have potential utility as ferro-magnetic shape memory alloys. Other SMAs, such as Fe-based alloys have better plastic deformation resistance but limited transformation strains $(<4 \%)$. The FeNiCoAlTi needs fine precipitates for slip resistance in an fcc matrix. It exhibits limited strains and large hysteresis and no superelastic behavior. The new FeMnAlNi based alloys (not shown in the figure) with bcc to fcc transformation exhibit surprising superelasticity [32], but low plastic flow resistance [33]. The Ti-Ta and $\mathrm{Ti}-\mathrm{Nb}$ alloys exhibit moderate transformation strains (6\% max.) and good plastic slip resistance depending on the ternary additions [34]. Further work is needed in Ti based SMAs before their potential utilization.

The transformation strain is also influenced by the propensity of some SMAs to show incomplete phase transformation which inhibits the achievement of the theoretical values. We draw a distinction between local strain measurements utilizing high resolution digital image correlation and the overall strain measurements using extensometry. In NiTiHf alloys, we emphasize that the local strain measurements are needed to gain an understanding of the intrinsic transformation strains because of spatial non uniformity of strains. In other SMAs, such as in high $\mathrm{Ni}(51.5 \% \mathrm{Ni}) \mathrm{NiTi}$ the strain fields were also nonuniform [28] with maximum value of $4 \%$ while in $<<51 \% \mathrm{Ni} \mathrm{NiTi}$ alloys the local and overall strains are found to be much closer[35] with maximum value of $10 \%$ in $50.1 \% \mathrm{Ni}[28]$. The spread of transformation strains (10\% to $2 \%$ ) in Figures $2-3$ for NiTi represent the results obtained from single crystals with compositions in the range $50.1 \% \mathrm{Ni}$ to $51.8 \% \mathrm{Ni}$ respectively.

In the case of $\mathrm{Ni}_{2} \mathrm{FeGa}$ [36] and $\mathrm{CuZnAl}$ alloys (unpublished), our DIC results show that the transformation zone spreads to the entire gage section upon large deformations, so the local and overall strains are similar at 12 and $9 \%$ respectively. Similarly, the strains have been found to be uniform across the gage length in $\mathrm{Ni}_{2} \mathrm{MnGa}$ 
[37]. For $\mathrm{Ni}_{2} \mathrm{MnGa}$, the results plotted in Figures 2-3 correspond to compression case because of the lack of ductility in tension. The transformation strain results in SMAs depend on the sample crystal orientation, therefore single crystals (or highly textured polycrystals) with maximum strain capability (intrinsic values) should be selected. These orientations are near [001] for $\mathrm{Ni}_{2} \mathrm{FeGa}, \mathrm{CuZnAl}, \mathrm{CoNiAl}$ and near [111] in NiTi alloys for tension. The strain magnitudes given in Figure 2-3 reflect these intrinsic, maximum strain values.

We note that the calculated martensite CRSS levels using DFT are rather high compared to austenite (for example $1.1 \mathrm{GPa}$ versus $0.63 \mathrm{GPa}$ for $\mathrm{NiFeGa}$ ). This is true for most SMAs. The austenite slip stress levels for SMAs $\left(\mathrm{Ni}_{2} \mathrm{FeGa}, \mathrm{Co}_{2} \mathrm{NiGa}, \mathrm{Co}_{2} \mathrm{NiAl}\right.$, $\mathrm{NiTi}, \mathrm{CuZn}$ and $\mathrm{Ni}_{2} \mathrm{TiHf}$ ) which possess the $\mathrm{L}_{2}$ and $\mathrm{B} 2$ cubic structures were predicted with PN (Peierls-Nabarro) theory [20, 38]. Interestingly, the critical stress for CuZn, is found to be $80 \mathrm{MPa}$. This alloy suffers from plastic deformation and exhibits the lowest levels. For austenitic NiTi the most likely slip system is (011)[100] with a CRSS of 0.71 GPa consistent with experiments. The theoretical calculations for CRSS in $\mathrm{Ni}_{2} \mathrm{FeGa}$, $\mathrm{Co}_{2} \mathrm{NiGa}, \mathrm{Co}_{2} \mathrm{NiA}, \mathrm{NiTi}, \mathrm{NiTiHf}_{25}$, and $\mathrm{CuZn}$ results in $0.63,0.76,0.72,0.71,0.78$ and $0.08 \mathrm{GPa}$ respectively [38]. These values are consistent with corresponding experimental values presented in [20, 39-48].

\subsection{Transformation Strain-Transformation Temperature Behavior of SMAs}

The transformation temperatures at $400^{\circ} \mathrm{C}$ and above makes NiTiHf alloys attractive candidates for high temperature SMA applications. We show examples of $\mathrm{NiTiHf}_{13.3}$ and $\mathrm{NiTiHf}_{25}$ results in Figure 3. Previous works explored the transformation temperatures with change in Hf contents in the range 15 to $20 \%$ [49-51]. Transformation temperatures less than $250^{\circ} \mathrm{C}$ have been reported depending on the $\mathrm{Ni} / \mathrm{Hf}$ content. The transformation temperatures for alloys with $\mathrm{Ni}$ content lower than $50 \%$ exhibit higher values compared to Ni-rich compositions but do not show superelasticity. Most recently, the use of $25 \% \mathrm{Hf}$ NiTiHf in nickel-rich polycrystals [52] resulted in higher transformation temperatures. Therefore, further presentation of experimental data on these alloys is of considerable interest. 
As stated earlier, the transformation temperatures in SMAs with good functional properties are typically less than $100^{\circ} \mathrm{C}$ for most cases (Figure 3). The most well-known NiTi alloys are utilized below $75^{\circ} \mathrm{C}$. Although the $\mathrm{NiFeGa}$ and $\mathrm{CoNiGa}(\mathrm{Al})$ alloys can exhibit superelasticity at temperatures above $75^{\circ} \mathrm{C}[30,31]$, their austenite finish temperature is less than $50^{\circ} \mathrm{C}$. Therefore, they can not be used as an actuator at high temperatures. The $\mathrm{CuZnAl}, \mathrm{CuNiAl}$, and FeNiCoTi alloys are limited to temperatures less than $100^{\circ} \mathrm{C}[2,10,11,22,53-56]$. The NiMnGa which exhibits useful SMA behavior at temperatures less than $100^{\circ}$ is utilized in the martensitic state [57, 58]. Recent introduction of $\mathrm{Nb}$, Ta, and Zr ternary elements [34, 59] in TiTa and TiNb alloys have opened new possibilities. The transformation temperatures of these alloys can approach $300^{\circ} \mathrm{C}$, but the transformation strains have been limited. The TiPd $[60,61]$ and TiAu $[62,63]$ alloys can reach higher transformation temperatures but have not been well studied, so they are not discussed in this paper. In perspective, they can benefit from further research to improve their mechanical properties.

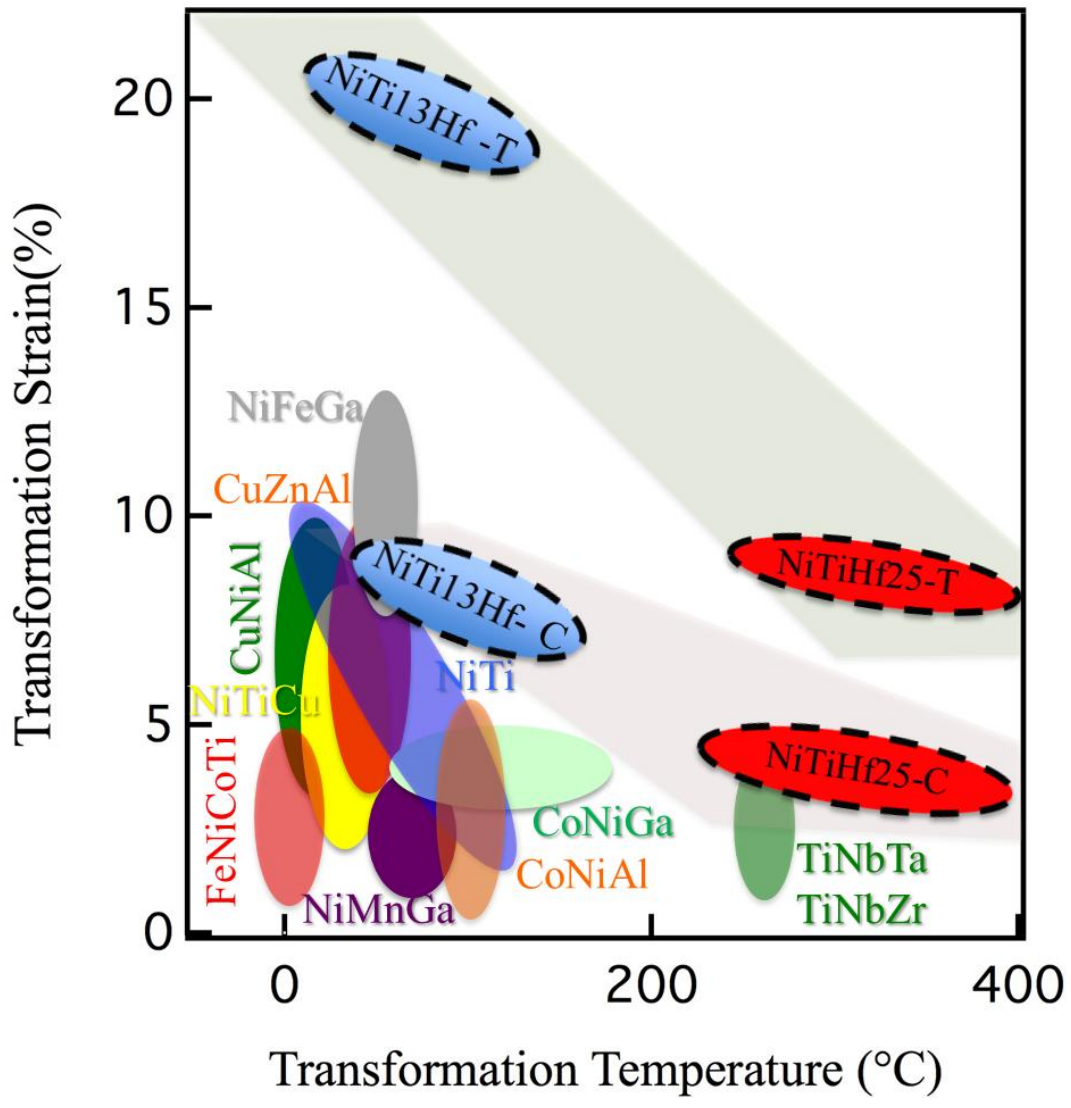


Figure 3 Transformation Strain-transformation temperature plot showing the most wellknown SMAs in comparison with the NiTiHf alloys.

\section{New Insights into NiTiHf Alloys- Towards Superior SMAs}

\subsection{Overview of Previous NiTiHf Work}

We provided an overview of the entire shape memory arena summarizing the most pertinent metrics in Figures 2 and 3. Early work on NiTiHf alloys has given insight on the physical metallurgy and metallurgical processing studies [64-66]. Few preliminary studies on the mechanical behavior of different Hf contents were made from early 2000, in particular focusing on the shape memory response of bent plates [67-69]. Because of elastic recovery and tension-compression symmetry it is difficult to interpret bending results. Shape memory behavior of bent samples displayed transformation strains up to $6.25 \%$ for the $\mathrm{Ni}_{49} \mathrm{Ti}_{36} \mathrm{Hf}_{15}$ composition [70,71], even though the low $\mathrm{Ni}$ content of this alloy $(<50 \%)$ precludes its usage as pseudoelastic material. In the last years the interest on the mechanical behavior of NiTiHf is growing, and several studies have shown good SME, ISME and SE behaviors at temperatures above $250^{\circ} \mathrm{C}$. Transformation strains up to $3.74 \%$ in polycrystal were obtained for the $\mathrm{Ni}_{50.3} \mathrm{Ti}_{29.7} \mathrm{Hf}_{20}$ composition [72-76]. Remarkably, pseudoelastic behavior was found at temperatures as high as $240^{\circ} \mathrm{C}$ [74]. In view of the promising results for the polycrystal, single crystals of $\mathrm{Ni}_{50.3} \mathrm{Ti}_{29.7} \mathrm{Hf}_{20}$ alloy showed only comparable level of transformation strains. The $\mathrm{Ni}_{50.3} \mathrm{Ti}_{29.7} \mathrm{Hf}_{20}$ [111] orientation was tested in isobaric compression experiments, and transformation strains up to $3.9 \%$ were measured [73]. However, further efforts in testing different crystal orientations ([001], [340], [678], [011]) did not lead to higher transformation strains. In our previous work, we selected a higher $\mathrm{Hf}$ content $(25 \%)$ in order to explore transformation temperatures higher than $250^{\circ} \mathrm{C}$. In compression, we obtained local transformation strains of $3.25 \%$ at temperatures higher than $265^{\circ} \mathrm{C}$ [77]. Even though the strain measurements refer to small domains in the polycrystalline material, the results show that, potentially, along specific crystal orientations the $\mathrm{NiTiHf}_{25}$ can promote concurrently high transformation strains and high transformation temperatures. Moreover, the Ni content con be properly manipulated in the compositional range of 50$51 \%$ in order to adjust transformations strains, temperatures and ductility. Regarding the 
slip resistance measurements in the literature, one needs to conduct deformation experiments near the $\mathrm{M}_{\mathrm{d}}$ temperature to precisely pinpoint its value. Such measurements were reported to be near $1000 \mathrm{MPa}$ for compositions of 20 and $12.5 \mathrm{Hf}[45,78]$. The results for the $25 \mathrm{Hf}$ alloys in our work also correspond to slip stress near $1000 \mathrm{MPa}$. We note that as the $\mathrm{Hf}$ increases the $\mathrm{M}_{\mathrm{d}}$ temperature shifts to higher value which makes these alloys even more attractive as possessing strength at high temperatures.

Now, we want to detail the new results on NiTiHf alloys which hold considerable promise. Specifically, the emphasis will be placed on plastic deformation resistance, transformation strains and transformation temperatures, three major considerations that govern the SMA response. As discussed above, the NiTiHf alloys have the potential to exhibit ultra-high strains and also possess high operational temperatures. We highlight these attributes with several figures given below.

\subsection{Experimental Results on NiTiHf}

In Figures 4 and 5, the results display the SE+SME and the SE behavior for the NiTiHf $_{13.3}$ case for tension and compression, respectively. The experimental techniques are provided in the Appendix. In $\mathrm{NiTiHf}_{13.3}$, the phase transformation is a consequence of cubic to monoclinic crystal lattice change under stress. Theoretically, the lattice constants and the monoclinic angle for NiTiHf favor high transformation strains. The first experiment in tension is conducted at $40^{\circ} \mathrm{C}$ which is slightly below the austenite finish temperature. The material undergoes a combined SE+SME behavior. The superelastic response $(2.5 \%)$ occurs upon unloading and the remnant strain $(15 \%)$ is recovered at zero stress upon heating to a critical temperature. This recovery at zero stress is termed the shape memory effect (SME). The total recoverable strain levels are near $18 \%$. We note that such a high transformation strain level can open new applications. Other experiments on the same alloy were conducted at higher temperatures $\left(50^{\circ} \mathrm{C}\right)$ with pure SE response and at low temperatures $\left(-35^{\circ} \mathrm{C}\right)$ with pure SME response [79]. The recoverable strains are in agreement with the values presented in Figure 4. In compression (Figure 5), we note that the SE response at room temperature with a recoverable strain exceeding $7 \%$ corresponds to stress levels of $1500 \mathrm{MPa}$. To our knowledge, SE at such high stresses 
combined with high strains $(>7 \%)$ is unprecedented for NiTi based alloys. In binary NiTi alloys, the compressive strains are limited to less than $5.5 \%$.

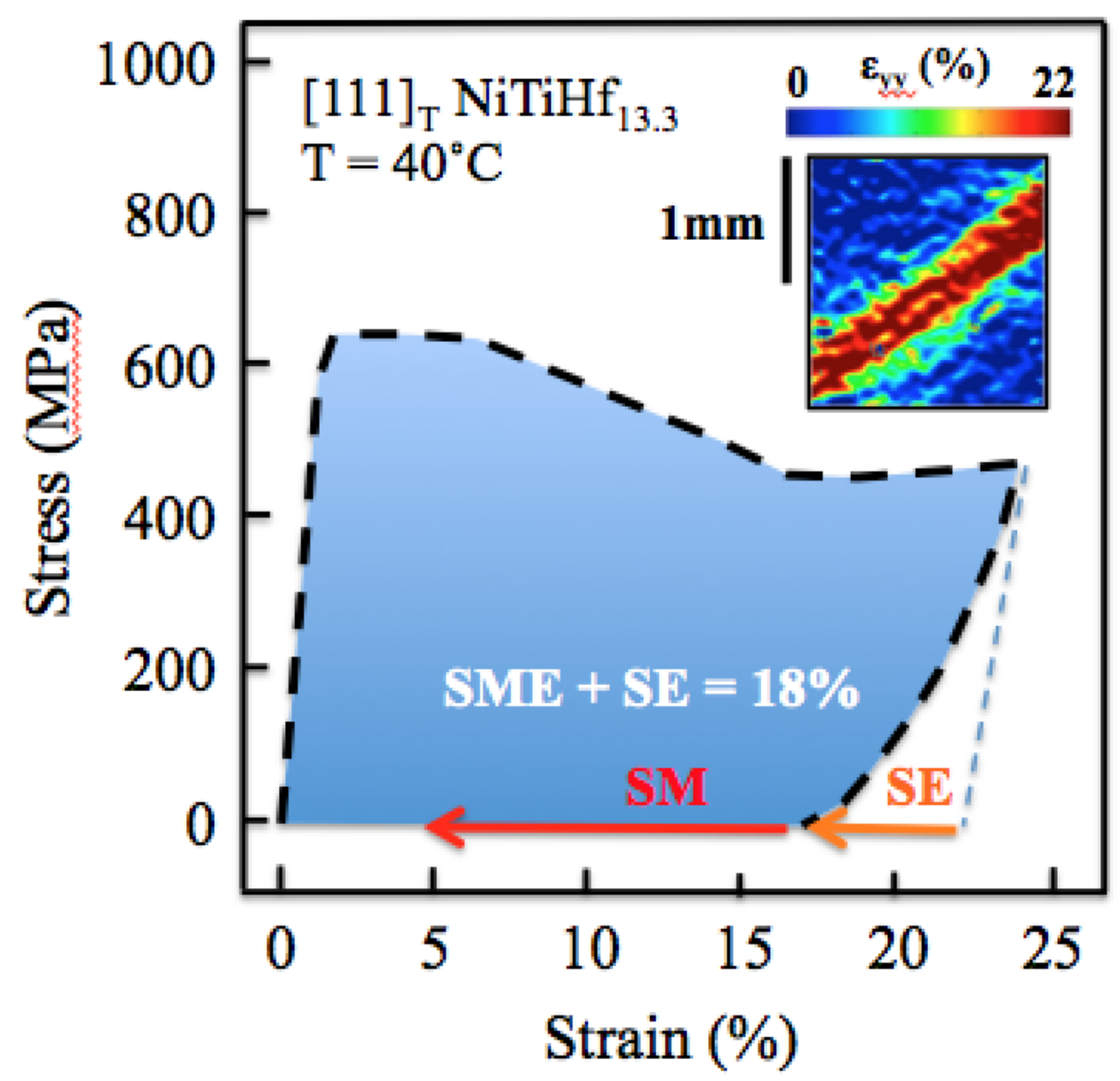

Figure 4. The stress-strain response of NiTi13Hf demonstrating recoverable strains near $18 \%$ which is remarkably high (based on [79]). 


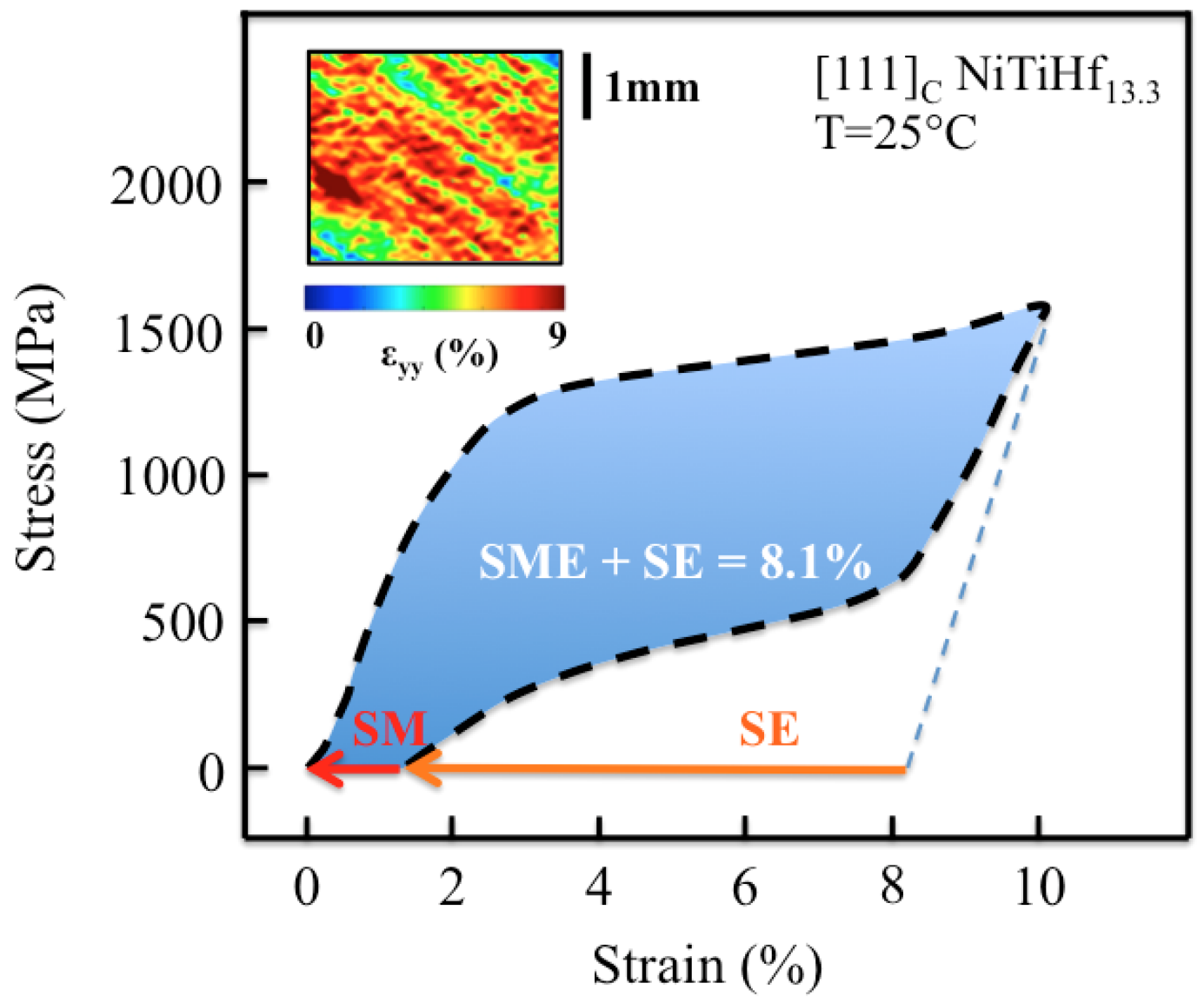

Figure 5. The stress-strain response of NiTi13Hf demonstrating strains above $8 \%$ with stress levels near 1500MPa (see also [79] ).

In Figures 6 and 7, the results for isobaric temperature cycling (ISME) are provided for the $\mathrm{NiTiHf}_{25}$ alloy for tension and compression, respectively. These experiments are begun by heating the alloy to high temperature and then applying a constant stress. During cooling and heating the stress is maintained constant. The images of the entire specimen surface are captured and stored for later analysis. The strain measurements at high magnifications represent the true transformation strains because the domains that are undergoing elastic deformation are excluded. We note that the strain distribution is more heterogeneous in tension compared to compression. The results show higher transformation strains in tension compared to compression with both values that are very high considering that the temperatures are near $450^{\circ} \mathrm{C}$. The results are shown for 
a cooling and heating cycle. Since both the transformation temperatures and the slip stresses in this alloy are high, these figures show excellent potential of $\mathrm{NiTiHf}_{25}$. The strains reported in Figures 6 and 7 are near $9 \%$ and $7 \%$ in tension and compression, respectively. In Figure 6, at the martensite start temperature, the strains increase in the tensile direction. Because elastic energy opposes the transformation, further undercooling is needed to continue the transformation as evident from the slope of the straintemperature curves [26]. Upon heating, the specimen reverts to austenite beginning at austenite start temperatures with the transformation completing at the austenite finish temperature. It is important to note that the thermal hysteresis associated with the transformation remains below $60^{\circ} \mathrm{C}$ despite the high operating temperatures. This data is obtained from reference [80]. 


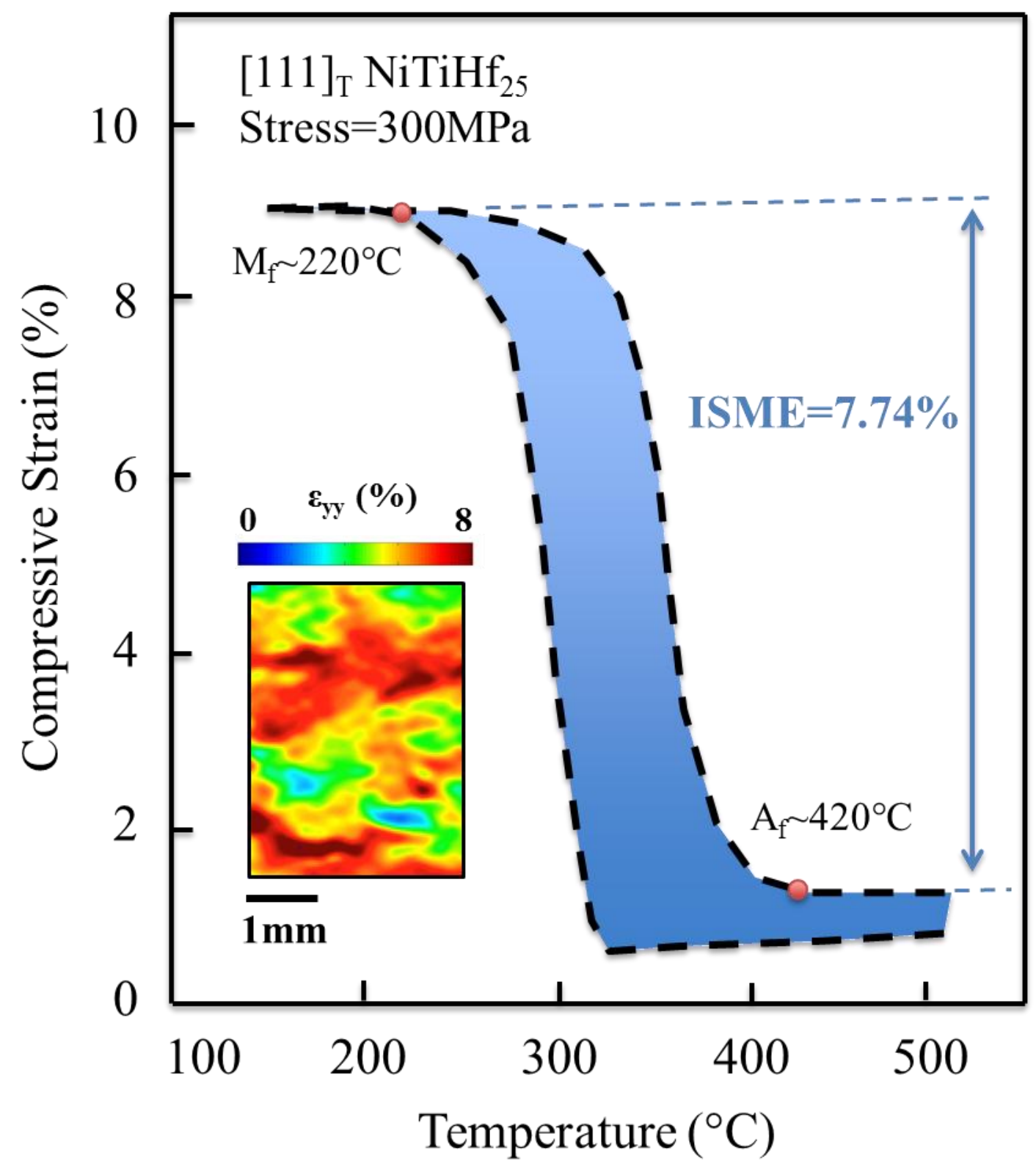

Figure 6. The strain-temperature response of $\mathrm{NiTiHf}_{25}$ demonstrating strains exceeding $7.7 \%$ with austenite finish temperature of $420^{\circ}$ (from reference [80] ). 


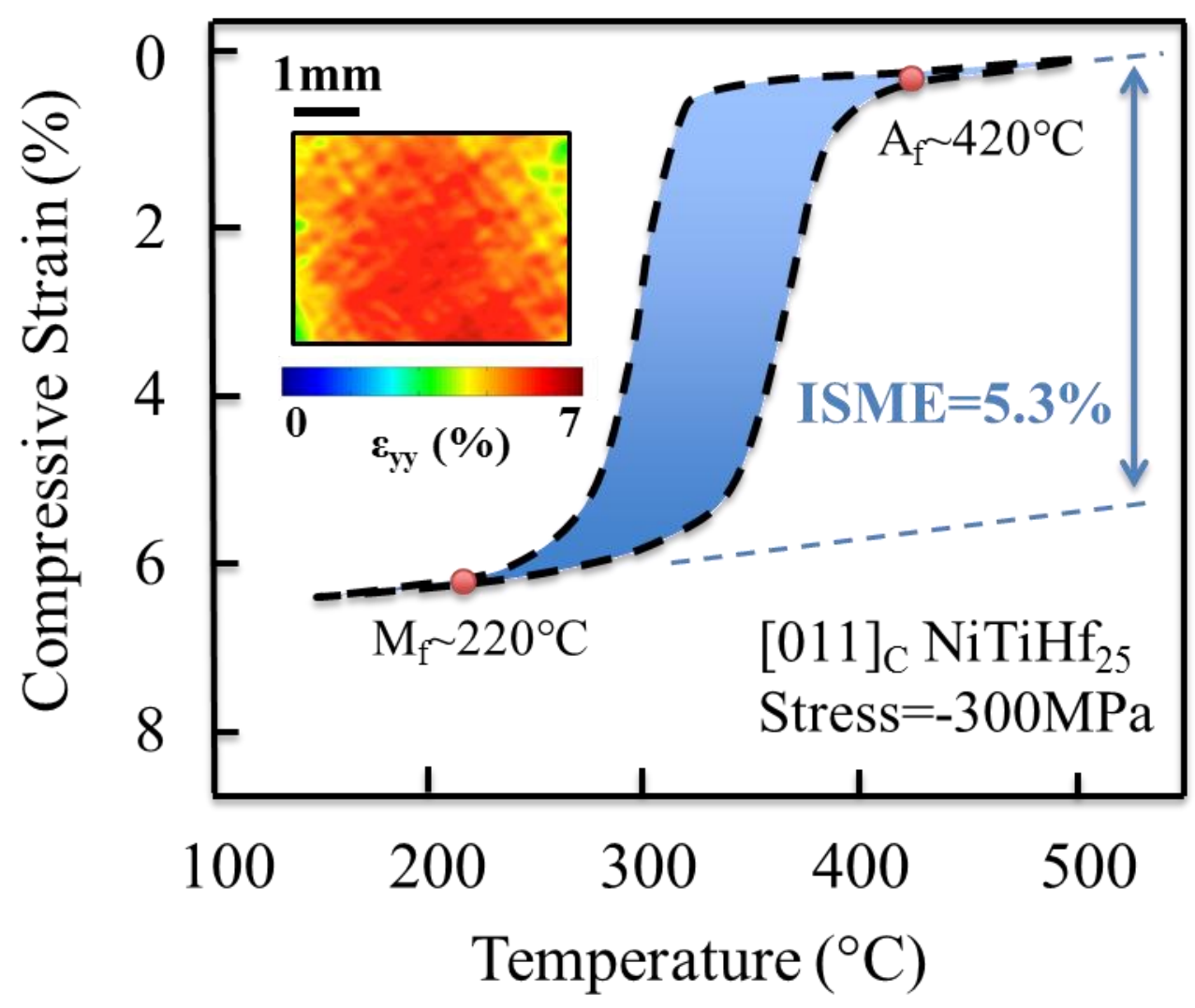

Figure 7. The strain-temperature response of $\mathrm{NiTiHf}_{25}$ demonstrating strains of $6 \%$ with austenite finish temperature of $420^{\circ}$ (based on [80]).

\section{Discussion of Results}

The search and discovery of new materials that far exceed the capabilities of the present ones must remain a tenet of research enterprise. This is particularly true for the shape memory alloy field because once can achieve significantly different behaviors in transformation strains, transformation temperatures with small changes in composition. The field evolved from $\mathrm{Cu}$ alloys to NiTi based alloys to encompass materials with exceedingly high strains, high temperatures and excellent resistance to plastic deformation. One must continue to seek compositions that favorably change the lattice constants hence result in large transformation strains. At the same time the alloys must possess considerable plastic deformation resistance to withstand such high strains in a thermo-elastic deformation. The high transformation temperature SMA NiTiHf alloys fulfill these functionalities. 
A natural question that arises is why the NiTiHf exhibits such high strengthening levels compared to other ternary additions. Among these ternary elements, Hf has the largest atomic radius exceeding the values for $\mathrm{Pt}, \mathrm{Pd}, \mathrm{Cu}$ and $\mathrm{Fe}$. The presence of $\mathrm{Hf}$ changes the bond lengths between $\mathrm{Ni}$ and $\mathrm{Ti}$ atoms within the lattice elevating the fault energy curves, hence the slip stresses [81]. Another factor is the presence of precipitates that impart slip resistance. The structure of precipitate has been reported by Santamarta et al. [30]. Essentially, the precipitate structure observed in the present alloys has been published earlier [78]. Figures 8 (a) and (b) indicate that there are three sets of B19' martensite plate consisting of $(001)_{\mathrm{B} 19}$, compound twins marked as $\mathrm{A}, \mathrm{B}$ and $\mathrm{C}$. There are also $1 / 3110^{*}{ }_{\mathrm{B} 2}$ type reflections derived from precipitate marked as $\mathrm{P}$ in Figure $8(\mathrm{~b})$. Further studies are needed on the role of precipitates on the transformation stress and hysteresis in view of their well-known influence in binary alloys.
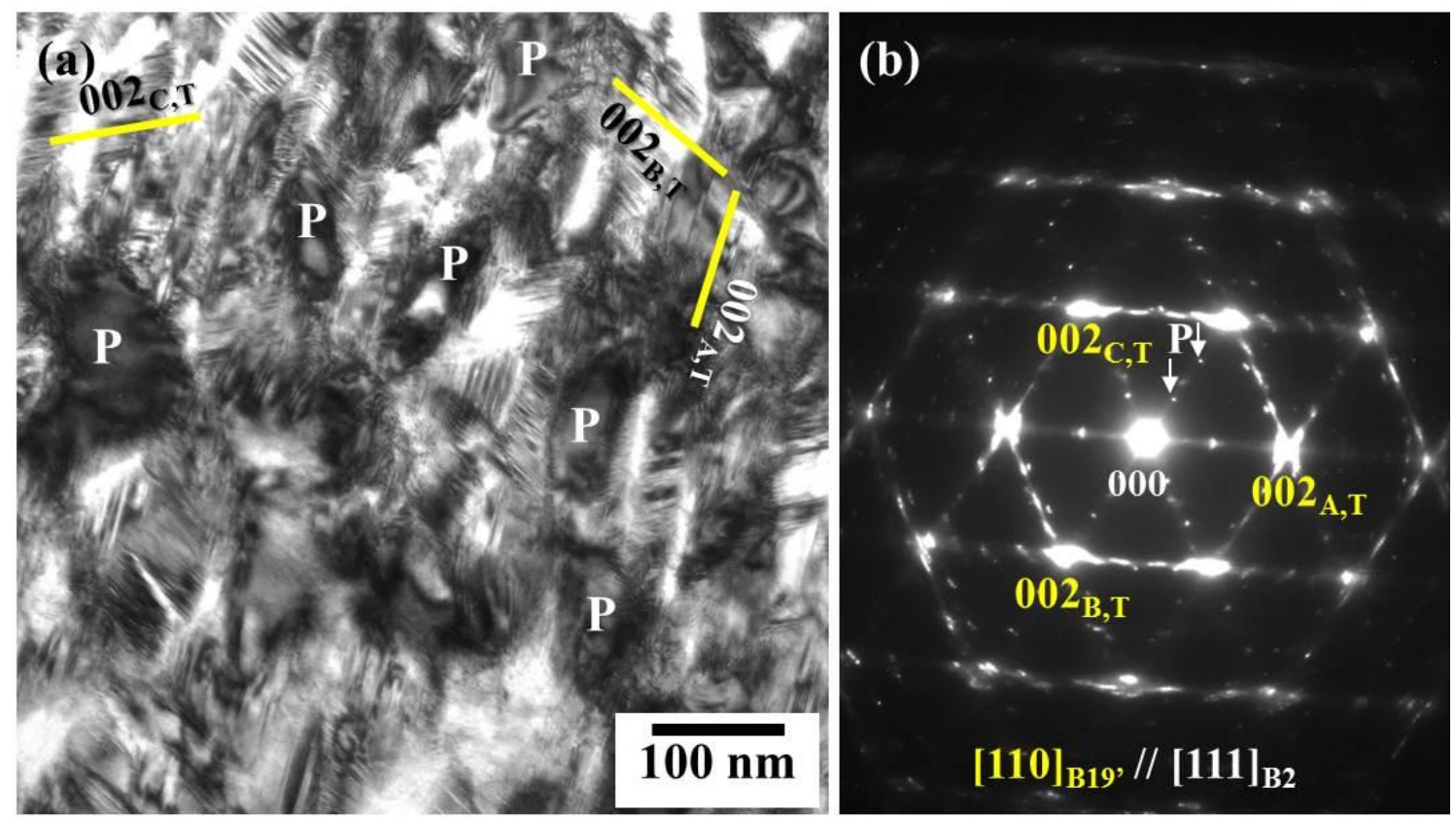

Figure 8. (a) Bright field image and (b) corresponding electron diffraction pattern. The pattern shows three sets of $(001)_{\mathrm{B} 19}$, compound twin and $1 / 3110 *_{\mathrm{B} 2}$ type from precipitate (P) (from [78]).

The other question has to do with the reasons behind the large transformation strains in NiTiHf alloys [82]. The lattice constants for austenite and martensite and the monoclinic angle of the martensite dictate the stretch tensors. Especially, the monocolinic 
angle increase can be substantial with increasing $\mathrm{Hf}$ content (from $96.8^{\circ}$ to $105.9^{\circ}$ for 25Hf). Further work is needed for enhanced understanding in this area. We note that one reason why the transformation strains are saturating as the Hf content is increased is due to the presence of increasing volume fraction of precipitates constituting domains which can not undergo transformation.

The results of this study shows that $\mathrm{NiTiHf}_{13.3}$ and $\mathrm{NiTiHf}_{25}$ exhibit ductilities as high as $22 \%$ and $10 \%$ in tension, respectively. These tensile ductilities exceed the fracture strains of many of the SMAs that are summarized in Figures 2 and 3. As discussed in early works [83], void nucleation and void coalescence at the matrix/precipitate interfaces are precursors to fracture. Therefore, the solutionized microstructural states may offer advantages in addition to texturing to have favorable orientations that circumvent the activation of $\{001\}$ and $\{110\}$ cleavage planes.

As previously discussed, the recent body of work on NiTiHf alloys [51, 73, 76, 84] has considered both polycrystals and single crystals for Hf contents less than $20 \%$. These recent works on compression have shown that the transformation strains fall far below the theoretical values [76]. A similar discrepancy has been observed in NiTi alloys in early work [27]. However, the reported difference between theory and experiment in NiTiHf alloys is far more severe. The present results overcome this seeming anomaly by making local DIC measurements and noting that there are substantial untransformed domains for both the $13.3 \mathrm{Hf}$ and $25 \mathrm{Hf}$ ternary compositions. Therefore, the overall measurements with extensometry may not be representative of the intrinsic transformation strains in SMAs with a heterogeneous microstructure.

The results underscore the advantages of studying a lower Hf content near $13 \mathrm{Hf} \%$ to provide a better assessment of transformation strain change with increasing Hf content. The $13 \mathrm{Hf}$ alloy present higher slip resistance compared to other ternary additions and demonstrate very high strains. At the local level, the strains can exceed $20 \%$ in experiments which points to possible role of reversible mechanical twinning contributing to additional strains. Unlike other SMAs the mechanical twinning is possibly reversible in the case NiTiHf alloys with high slip resistance. Theoretical calculations of twinning stress confirm its operation well below the slip stress [81]. Further work is needed to explain the origin of such high reversible strains. 
Other measures of SMA performance can be studied but are viewed as application specific. For example, the work output of shape memory alloys can be an important consideration in actuators. The work output is defined as stress times the transformation strain in an ISME experiment. Work outputs exceeding $20 \mathrm{~J} / \mathrm{m} 2$ are considered to be exceptional. Another parameter is the thermal/stress hysteresis which is an important quantity in an actuator and in damping respectively. Thermal hysteresis is the width of the strain-temperature curves in an ISME experiment [26]. In NiTi the range is between 40 to $80^{\circ}$ [26] which is similar in NiTiHf alloys $\left(50^{\circ} \mathrm{C}\right.$ on the average as shown in Figures 6 and 7). The R-Phase in NiTi is considered to have tiny hysteresis, albeit with small transformation strains, and has found niche applications. The NiFeGa alloys exhibit exceptionally low thermal hysteresis[31]. There are ongoing explorations of alternative ferromagnetic shape memory alloys (Fe and Co based) [85] to NiMnGa to achieve functionality in tension and improve ductility. For superior ferromagnetic shape memory, the elastic strain energy needs to be low while the magnetic anisotropy energy has to be high to overcome the elastic strain energy. So far, the NiMnGa remains the best ferromagnetic shape memory alloy. The cost of the SMAs is another important metric. The addition of $\mathrm{Pd}, \mathrm{Pt}, \mathrm{Au}$ to binary NiTi has been considered but these ternary elements are very expensive. The Hf is also an expensive element and worthy of specialized high temperature applications. Other alloys such as $\mathrm{Ni} 2 \mathrm{MnGa}$, Ni2FeGa are also costly because of the presence of gallium. The $\mathrm{Cu}$ and $\mathrm{Fe}$ based SMAs are less costly compared to the nickel and titanium based alloys. More details regarding the cost analysis are left aside for future papers. Finally, the entropy change associated with transformation can be an important consideration to maximize thermo-elastocaloric effects [35], ie. cooling magnitudes. The entropy change correlates with the slope of the transformation stresstemperature curve which is unusually high for $\mathrm{NiTiHf}_{13.3}$ alloy opening new possibilities [78]. Among SMAs the NiTi alloys possess some of the largest entropy changes [86]. These other considerations are left aside for future research reviews.

\section{Conclusions and Future Directions}

An overview of the shape memory field is given summarizing the capabilities of the current shape memory alloys. The work supports the following: 
(1) Three key parameters that govern SMA functionality were identified. They are transformation strain, transformation temperature and plastic slip resistance. We provide a summary of the most important SMAs highlighting these three parameters.

(2) The current SMAs have served the community well with transformation strain levels near $10 \%$ and transformation temperature levels less than $75^{\circ} \mathrm{C}$. The slip resistance $(<<1000 \mathrm{MPa})$ has limited the widespread utilization of a number of SMAs where fatigue and fracture resistance is of paramount importance.

(3) The present results underscore the need for high transformation temperatures $\left(>400^{\circ} \mathrm{C}\right)$ and high transformation strains $(>20 \%)$. We used a mutiscale approach to measure the transformation strains in NiTiHf alloys precisely, demonstrating superlative functionalities. The results are convincing and repeatable. Our results and experiments (SME, SE and ISME behaviors) notwithstanding, we point to the need for study of new class of SMAs.

(4) Further work is needed to optimize the compositions and heat treatments as the NiTi alloys with ternary additions such as NiTiHf are rather complex in their response and in their underlying microstructure.

\section{Acknowledgements}

The work is supported by a National Science Foundation grant NSF CMMI1333884 which is gratefully acknowledged. The single crystals of NiTiHf were grown by Prof. Yuriy Chumlyakov. The authors of the paper thank the reviewers for their valuable comments.

\section{A1. Appendix -}

\section{Experimental Techniques}


The NiTiHf single crystals reported in this study were grown by the Bridgman technique in He atmosphere. The rods were sectioned into disks parallel to the (011) crystallographic plane using electrical discharge machining. For the $\mathrm{NiTiHf}_{25}$ composition the tensile specimens were successively cut along the [111] orientation, while the compression specimens along the [011] orientation. For the $\mathrm{NiTiHf}_{13.3}$ composition both the tensile and compression specimens were cut along the [111] orientation. The characterization of the microstructure can be found in Ref.[78].The tensile specimens were shaped into dog-bone geometry with $3 \mathrm{~mm} \times 1.5 \mathrm{~mm}$ net section and $10 \mathrm{~mm}$ gauge length, while the compression specimens were sectioned into $4 \mathrm{~mm} \mathrm{x}$ $4 \mathrm{~mm} \times 9 \mathrm{~mm}$ geometry.

\section{Digital Image Correlation}

The strain measurements are made with advanced digital image correlation (DIC) methods. In DIC, images of the deformed region of interest are correlated to a reference image (of the same region prior to deformation) to make full-field measurements of displacements. The in-plane strain fields are calculated, afterwards, through differentiation of the vertical and horizontal displacement fields [87]. The resolution of the strain field depends on the magnification at which reference and deformed images are captured [88]. For the experiments presented in this work, the compression and tension specimens were initially polished with abrasive paper up to 1800 grit. The speckle pattern for DIC strain measurements was deposited using an Iwata Micron B airbrush and a black paint for high temperature applications. The images were successively captured with a resolution ranging between $2 \mu \mathrm{m} / \mathrm{px}$ and $3 \mu \mathrm{m} / \mathrm{px}$. The DIC contour plots in Figures 4 to 7 always display the axial component (parallel to the load direction) of the strain tensor. By considering single crystals and using digital image correlation it is possible to make measurements without the grain boundary effects that can produce superfluous strain gradients.

Prior to loading, the orientations of the specimens were verified with X-ray diffraction performed on a Philips Xpert 2 diffractometer using $\mathrm{Cu} \mathrm{K \alpha}$ radiation. For the $\mathrm{NiTiHf}_{25}$ alloy, the X-ray diffraction orientation data were acquired at $500^{\circ} \mathrm{C}$ in the fully austenitic phase. 


\section{Tension and Compression Experiments}

The tension and compression experiments were conducted on a servo-hydraulic machine under quasi-static conditions. The load frame was controlled with a customized Labview program. For both tension and compression isothermal experiments the loading was conducted under displacement control and unloading was performed under stress control providing an average strain rate of $10^{-3} \mathrm{sec}^{-1}$. The specimen surface images were obtained synchronously with the load data and stored for later analysis. During isothermal deformation the images were captured every 2 seconds. The temperature of the specimens was measured using a Epsilon laser based measurement system. The specimens were heated with a Lepel $2.5 \mathrm{~kW}$ Induction Heater. Specimen cooling was obtained in air for the high temperature $\mathrm{NiTiHf}_{25}$ alloy, while we used liquid nitrogen in order to cool the grips for the experiments on the $\mathrm{NiTiHf}_{13.3}$ alloy.

During isobaric experiments one initial reference image was captured at the maximum temperature and at zero stress. At the maximum temperature the constant stress was successively applied and a second image captured. Successively, the images for DIC were manually captured every $5^{\circ} \mathrm{C}$. To input the NiTiHf results into Figures 2 and 3 we conducted in excess of 75 experiments in total. 


\section{References}

[1] Otsuka K, Wayman CM. Shape Memory Materials. Cambridge: Cambridge University Press; 1998.

[2] T.W. Duerig KNM, D. Stöckel, C.M. Wayman, Editors. Engineering Aspects of Shape Memory Alloys, . Butterworth-Heinemann, Boston 1990.

[3] Funakubo H. Shape Memory Alloys. Gordon and Breach Science Publishers 1987; (translated from the Japanese by J.B. Kennedy)

[4] Perkins J. Shape Memory Effects in Alloys. Springer US Publisher 1975.

[5] Sehitoglu H. A New Journal Helping to Shape the Future of Materials. Shap Mem Superelasticity 2015;1:1-3.

[6] Delaey L, Krishnan RV, Tas H, Warlimont H. Thermoelasticity, pseudoelasticity and the memory effects associated with martensitic transformations. Journal of Materials Science 1974;9:1521-35.

[7] Damiani C, Lovey FC, Sade M. Plastic deformation under compression of $\mathrm{Cu}-\mathrm{Zn}-\mathrm{Al}$ martensitic single crystals. Materials Science \&amp; Engineering A (Structural Materials: Properties, Microstructure and Processing) 2002;A323:436-44.

[8] Sade M, Hornbogen E. Fatigue of single- and polycrystalline -CuZn-base shape memory alloys. Zeitschrift fur Metallkunde 1988;79:782-7.

[9] Delaey L, Janssen J, Van de Mosselaer D, Dullenkopf G, Deruyttere A. Fatigue

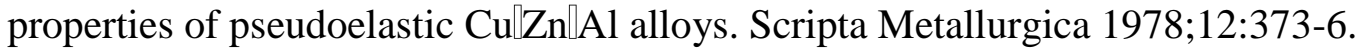

[10] Brown LC. The fatigue of pseudoelastic single crystals of -CuAlNi. Metallurgical Transactions A (Physical Metallurgy and Materials Science) 1979;104:217-24.

[11] Melton KN, Mercier O. Fatigue of NiTi and CuZnAl shape memory alloys. Strength of Metals and Alloys 5th International Conference, 27-31 Aug 1979. New York, NY, USA: Pergamon; 1979. p. 1243-8.

[12] Buehler WJ, Gilfrich JV, Wiley RC. Effect of Low-Temperature Phase Changes on the Mechanical Properties of Alloys near Composition TiNi. Journal of Applied Physics 1963;34:1475-7.

[13] Gall K, Maier HJ. Cyclic deformation mechanisms in precipitated NiTi shape memory alloys. Acta Materialia 2002;50:4643-57. 
[14] Strnadel B, Ohashi S, Ohtsuka H, Miyazaki S, Ishihara T. Effect of mechanical cycling on the pseudoelasticity characteristics of $\mathrm{Ti}[\mathrm{Ni}$ and $\mathrm{Ti} \llbracket \mathrm{Ni}\lceil\mathrm{Cu}$ alloys. Materials Science and Engineering: A 1995;203:187-96.

[15] Miyazaki S, Kimura S, Takei F, Miura T, Otsuka K, Suzuki Y. Shape memory effect and pseudoelasticity in a Ti-Ni single crystal. Scripta Metallurgica 1983;17:1057-62.

[16] Miyazaki S, Otsuka K, Suzuki Y. Transformation pseudoelasticity and deformation behavior in a Ti-50.6at\%Ni alloy. Scripta Metallurgica 1981;15:287-92.

[17] Sehitoglu H, Karaman I, Anderson R, Zhang X, Gall K, Maier H, Chumlyakov Y. Compressive response of NiTi single crystals. Acta Materialia 2000;48:3311-26.

[18] Ma J, Karaman I, Noebe RD. High temperature shape memory alloys. International Materials Reviews 2010;55:257-315.

[19] Gall K, Sehitoglu H. The role of texture in tension-compression asymmetry in polycrystalline NiTi. International Journal of Plasticity 1999;15:69.

[20] Ezaz T, Wang J, Sehitoglu H, Maier HJ. Plastic deformation of NiTi shape memory alloys. Acta Materialia 2013;61:67-78.

[21] Sehitoglu H, Efstathiou C, Maier HJ, Chumlyakov Y. Hysteresis and deformation mechanisms of transforming FeNiCoTi. Mechanics of Materials 2006;38:538.

[22] Sehitoglu H, Zhang XY, Kotil T, Canadinc D, Chumlyakov Y, Maier HJ. Shape memory behavior of FeNiCoTi single and polycrystals. Metallurgical and Materials Transactions A (Physical Metallurgy and Materials Science) 2002;33A:3661.

[23] Chumlyakov YI, Kireeva IV, Kutz OA, Turabi AS, Karaca HE, Karaman I. Unusual reversible twinning modes and giant superelastic strains in FeNiCoAlNb single crystals. Scripta Materialia 2016;119:43-6.

[24] Tseng LW, Ma J, Karaman I, Wang SJ, Chumlyakov YI. Superelastic response of the FeNiCoAlTi single crystals under tension and compression. Scripta Materialia 2015;101:1-4.

[25] Wagoner Johnson AJ, Hamilton RF, Sehitoglu H, Biallas G, Maier HJ, Chumlyakov YI, Woo HS. Analysis of multistep transformations in single-crystal NiTi. Metallurgical and Materials Transactions A (Physical Metallurgy and Materials Science) 2005;36A:919-28. 
[26] Hamilton RF, Sehitoglu H, Chumlyakov Y, Maier HJ. Stress dependence of the hysteresis in single crystal NiTi alloys. Acta Materialia 2004;52:3383.

[27] Sehitoglu H, Hamilton R, Canadinc D, Zhang XY, Gall K, Karaman I, Chumlyakov Y, Maier HJ. Detwinning in NiTi alloys. Metallurgical and Materials Transactions A: Physical Metallurgy and Materials Science 2003;34:5-13.

[28] Efstathiou C, Sehitoglu H. Local transformation strain measurements in precipitated NiTi single crystals. Scripta Materialia 2008;59:1263.

[29] Chumlyakov YI, Kireeva IV, Panchenko EY, Timofeeva EE, Pobedennaya ZV, Chusov SV, Karaman I, Maier H, Cesari E, Kirillov VA. High-temperature superelasticity in CoNiGa, CoNiAl, NiFeGa, and TiNi monocrystals. Russian Physics Journal 2008;51:1016-36.

[30] Hamilton RF, Sehitoglu H, Efstathiou C, Maier HJ, Chumlyakov Y. Pseudoelasticity in Co-Ni-Al single and polycrystals. Acta Materialia 2006;54:587.

[31] Hamilton RF, Sehitoglu H, Efstathiou C, Maier HJ. Inter-martensitic transitions in Ni-Fe-Ga single crystals. Acta Materialia 2007;55:4867-76.

[32] Tanaka Y, Himuro Y, Kainuma R, Sutou Y, Omori T, Ishida K. Ferrous polycrystalline shape-memory alloy showing huge superelasticity. Science 2010;327:1488-90.

[33] Tseng LW, Ma J, Wang SJ, Karaman I, Kaya M, Luo ZP, Chumlyakov YI. Superelastic response of a single crystalline FeMnAlNi shape memory alloy under tension and compression. Acta Materialia 2015;89:374-83.

[34] Buenconsejo PJS, Kim HY, Hosoda H, Miyazaki S. Shape memory behavior of TiTa and its potential as a high-temperature shape memory alloy. Acta Materialia 2009;57:1068-77.

[35] Pataky GJ, Ertekin E, Sehitoglu H. Elastocaloric cooling potential of NiTi, Ni2FeGa, and CoNiAl. Acta Materialia 2015;96:420-7.

[36] Efstathiou C, Sehitoglu H, Carroll J, Lambros J, Maier HJ. Full-field strain evolution during intermartensitic transformations in single-crystal NiFeGa. Acta Materialia 2008;56:3791-9. 
[37] Hamilton R, Dilibal S, Sehitoglu H, Maier H. Underlying mechanism of dual hysteresis in NiMnGa single crystals. Materials Science and Engineering: A 2011;528:1877-81.

[38] Wang J, Sehitoglu H, Maier HJ. Dislocation slip stress prediction in shape memory alloys. International Journal of Plasticity 2013; In press.

[39] Chumlyakov Y, Kireeva I, Panchenko E, Timofeeva E, Pobedennaya Z, Chusov S, Karaman I, Maier H, Cesari E, Kirillov V. High-temperature superelasticity in CoNiGa, CoNiAl, NiFeGa, and TiNi monocrystals. Russian Physics Journal 2008;51:1016-36.

[40] Karaman I, Lagoudas DC. Magnetic Shape Memory Alloys with High Actuation Forces. DTIC Document; 2006.

[41] Dilibal S, Sehitoglu H, Hamilton R, Maier H, Chumlyakov Y. On the volume change in $\mathrm{Co}-\mathrm{Ni}-\mathrm{Al}$ during pseudoelasticity. Materials Science and Engineering: A 2011;528:2875-81.

[42] Efstathiou C, Sehitoglu H. Local transformation strain measurements in precipitated NiTi single crystals. Scripta Materialia 2008;59:1263-6.

[43] Chumlyakov Y, Kireeva I, Panchenko E, Timofeeva E, Pobedennaya Z, Chusov S, Karaman I, Maier H, Cesari E, Kirillov V. High-temperature superelasticity in CoNiGa, CoNiAl, NiFeGa, and TiNi monocrystals. Russian Physics Journal 2008;51:1016-36.

[44] Sehitoglu H, Jun J, Zhang X, Karaman I, Chumlyakov Y, Maier HJ, Gall K. Shape memory and pseudoelastic behavior of $51.5 \% \mathrm{Ni}$-Ti single crystals in solutionized and overaged state. Acta Materialia 2001;49:3609-20.

[45] Coughlin D, Phillips P, Bigelow G, Garg A, Noebe R, Mills M. Characterization of the microstructure and mechanical properties of a $50.3 \mathrm{Ni}-29.7 \mathrm{Ti}-20 \mathrm{Hf}$ shape memory alloy. Scripta Materialia 2012.

[46] Wang Y, Zheng Y, Cai W, Zhao L. The tensile behavior of Ti36Ni49Hf15 high temperature shape memory alloy. Scripta Materialia 1999;40:1327-31.

[47] Romero R, Lovey F, Ahlers M. Plasticity in $\mathrm{E} \leq$ phase $\mathrm{Cu}-\mathrm{Zn}-\mathrm{Al}$ alloys. Philosophical Magazine A 1988;58:881-903.

[48] Wollmershauser JA, Kabra S, Agnew SR. In situ neutron diffraction study of the plastic deformation mechanisms of B2 ordered intermetallic alloys: NiAl, CuZn, and CeAg. Acta Materialia 2009;57:213-23. 
[49] Karaca H, Saghaian S, Basaran B, Bigelow G, Noebe R, Chumlyakov Y. Compressive response of nickel-rich NiTiHf high-temperature shape memory single crystals along the [111] orientation. Scripta Materialia 2011;65:577-80.

[50] Stebner AP, Bigelow GS, Jin Y, Shukla DP, Saghaian SM, Rogers R, Garg A, Karaca HE, Chumlyakov Y, Bhattacharya K, Noebe RD. Transformation strains and temperatures of a nickel-titanium-hafnium high temperature shape memory alloy. Acta Materialia 2014;76:40-53.

[51] Evirgen A, Karaman I, Santamarta R, Pons J, Noebe RD. Microstructural characterization and shape memory characteristics of the Ni50.3Ti34.7Hf15 shape memory alloy. Acta Materialia 2015;83:48-60.

[52] Patriarca L, Sehitoglu H. High-temperature superelasticity of Ni 50.6 Ti 24.4 Hf 25.0 shape memory alloy. Scripta Materialia 2015.

[53] Stalmans R, Van Humbeeck J, Delaey L. Degradation of the shape memory effect in copper-base alloys. Scripta Metallurgica et Materialia 1994;31:1573-6.

[54] Stalmans R, van Humbeeck J, Delaey L. Thermomechanical cycling, two way memory and concomitant effects in $\mathrm{Cu}-\mathrm{Zn}-\mathrm{Al}$ alloys. Acta Metallurgica et Materialia 1992;40:501-11.

[55] Friend CM, Manosa L, Ortin J, Planes A. A calorimetric investigation of martensitic transformation under applied stress in single crystal $\mathrm{Cu}-\mathrm{Al}-\mathrm{Ni}$ alloys. European Symposium on Martensitic Transformation and Shape Memory Properties, 16-18 Sept 1991. C4 ed. France1991. p. 71-6.

[56] Van Humbeeck J, Van Hulle D, Delaey L, Ortin J, Segui C, Torra V. A two-stage martensite transformation in a $\mathrm{Cu}-13.99$ mass\% Al-3.5 mass\% Ni alloy. Transactions of the Japan Institute of Metals 1987;28:383-91.

[57] Webster PJ, Ziebeck KRA, Town SL, Peak MS. Magnetic order and phase transformation in Ni2MnGa. Philosophical Magazine Part B 1984;49:295-310.

[58] Sozinov A, Likhachev AA, Lanska N, Ullakko K. Giant magnetic-field-induced strain in NiMnGa seven-layered martensitic phase. Applied Physics Letters 2002;80:1746-8. 
[59] Miyazaki S, Kim HY, Hosoda H. Development and characterization of Ni-free Tibase shape memory and superelastic alloys. Materials Science and Engineering: A 2006;438:18-24.

[60] Nishida M, Hara T, Morizono Y, Ikeya A, Kijima H, Chiba A. Transmission electron microscopy of twins in martensite in Ti-Pd shape memory alloy. Acta Materialia 1997;45:4847-53.

[61] Arockiakumar R, Takahashi M, Takahashi S, Yamabe-Mitarai Y. Microstructure, mechanical and shape memory properties of $\mathrm{Ti}-55 \mathrm{Pd}-5 \mathrm{x}(\mathrm{x}=\mathrm{Zr}, \mathrm{Hf}, \mathrm{V}, \mathrm{Nb})$ alloys. Materials Science and Engineering: A 2013;585:86-93.

[62] Declairieux C, Denquin A, Ochin P, Portier R, Vermaut P. On the potential of Ti50Au50 compound as a high temperature shape memory alloy. Intermetallics 2011;19:1461-5.

[63] Vermaut P, Declairieux C, Ochin P, Kolomytsev V, Pasko A, Monastyrsky G, Denquin A, Portier R. Martensitic transformation and shape memory effect at very high temperatures in $\mathrm{HfPd}$, and $\mathrm{TiAu}$ intermetallic compounds. Journal of Alloys and Compounds 2013;577:388-92.

[64] Potapov P, Shelyakov A, Gulyaev A, Svistunov E, Matveeva N, Hodgson D. Effect of Hf on the structure of Ni-Ti martensitic alloys. Materials Letters 1997;32:247-50.

[65] Besseghini S, Villa E, Tuissi A. Ni[Ti $[$ Hf shape memory alloy: effect of aging and thermal cycling. Materials Science and Engineering: A 1999;273-275:390-4.

[66] Thoma PE, Boehm JJ. Effect of composition on the amount of second phase and transformation temperatures of NixTi90-xHf10 shape memory alloys. Materials Science and Engineering: A 1999;273-275:385-9.

[67] Wang YQ, Zheng YF, Cai W, Zhao LC. The tensile behavior of Ti36Ni49Hf15 high temperature shape memory alloy. Scripta Materialia 1999;40:1327-31.

[68] Kockar B, Karaman I, Kim JI, Chumlyakov Y. A method to enhance cyclic reversibility of NiTiHf high temperature shape memory alloys. Scripta Materialia 2006;54:2203-8.

[69] Meng XL, Cai W, Fu YD, Li QF, Zhang JX, Zhao LC. Shape-memory behaviors in an aged Ni-rich TiNiHf high temperature shape-memory alloy. Intermetallics 2008;16:698-705. 
[70] Javadi MM, Belbasi M, Salehi MT, Afshar MR. Effect of aging on the microstructure and shape memory effect of a hot-rolled NiTiHf alloy. Journal of Materials Engineering and Performance 2011;20:618-22.

[71] Moshref-Javadi M, Seyedein SH, Salehi MT, Aboutalebi MR. Age-induced multistage transformation in a Ni-rich NiTiHf alloy. Acta Materialia 2013;61:2583-94.

[72] Bigelow GS, Garg A, Padula Ii SA, Gaydosh DJ, Noebe RD. Load-biased shapememory and superelastic properties of a precipitation strengthened high-temperature $\mathrm{Ni}$ 50.3Ti 29.7Hf 20 alloy. Scripta Materialia 2011;64:725-8.

[73] Karaca HE, Saghaian SM, Basaran B, Bigelow GS, Noebe RD, Chumlyakov YI. Compressive response of nickel-rich NiTiHf high-temperature shape memory single crystals along the [llll 11 l] orientation. Scripta Materialia 2011;65:577-80.

[74] Karaca HE, Saghaian SM, Ded G, Tobe H, Basaran B, Maier HJ, Noebe RD, Chumlyakov YI. Effects of nanoprecipitation on the shape memory and material properties of an Ni-rich NiTiHf high temperature shape memory alloy. Acta Materialia 2013;61:7422-31.

[75] Benafan O, Garg A, Noebe RD, Bigelow GS, Padula Ii SA, Gaydosh DJ, Schell N, Mabe JH, Vaidyanathan R. Mechanical and functional behavior of a Ni-rich Ni50.3Ti 29.7Hf20 high temperature shape memory alloy. Intermetallics 2014;50:94-107.

[76] Stebner AP, Bigelow GS, Yang J, Shukla DP, Saghaian SM, Rogers R, Garg A, Karaca HE, Chumlyakov Y, Bhattacharya K, Noebe RD. Transformation strains and temperatures of a nickel-titanium-hafnium high temperature shape memory alloy. Acta Materialia 2014;76:40-53.

[77] Patriarca L, Sehitoglu H. High-temperature superelasticity of Ni50.6Ti24.4Hf25.0 shape memory alloy. Scripta Materialia 2015;101:12-5.

[78] Wu Y, Patriarca L, Li G, Sehitoglu H, Soejima Y, Ito T, Nishida M. Shape Memory Response of Polycrystalline NiTi12.5Hf Alloy: Transformation at Small Scales. Shap Mem Superelasticity 2015;1:387-97.

[79] Wu Y, Patriarca L, Sehitoglu H, Chumlyakov Y. Ultrahigh tensile transformation strains in new Ni50.5Ti36.2Hf13.3 shape memory alloy. Scripta Materialia 2016;118:514. 
[80] Patriarca L, Wu Y, Sehitoglu H, Chumlyakov YI. High temperature shape memory behavior of Ni50.3Ti25Hf24.7 single crystals. Scripta Materialia 2016;115:133-6.

[81] Wang J, Sehitoglu H. Modelling of martensite slip and twinning in NiTiHf shape memory alloys. Philosophical Magazine 2014;94:2297-317.

[82] Wu Y, Ojha A, Patriarca L, Sehitoglu H. Fatigue Crack Growth Fundamentals in Shape Memory Alloys. Shap Mem Superelasticity 2015;1:18-40.

[83] Chumlyakov Y, Efimenko S, Kireeva I, Panchenko E, Sehitogly H, Gall K, Yahia H. Effects of shape memory and superelasticity in aged TiNi single crystals. Doklady Physics 2001;46:849-52.

[84] Saghaian SM, Karaca HE, Tobe H, Souri M, Noebe R, Chumlyakov YI. Effects of aging on the shape memory behavior of Ni-rich Ni50.3Ti29.7Hf20 single crystals. Acta Materialia 2015;87:128-41.

[85] Pons J, Cesari E, Seguí C, Masdeu F, Santamarta R. Ferromagnetic shape memory alloys: Alternatives to Ni-Mn-Ga. Materials Science and Engineering: A 2008;481482:57-65.

[86] Niitsu K, Kimura Y, Xu X, Kainuma R. Composition Dependences of Entropy Change and Transformation Temperatures in Ni-rich Ti-Ni System. Shap Mem Superelasticity 2015;1:124-31.

[87] Sutton MA, Wolters WJ, Peters WH, Ranson WF, McNeill SR. Determination of displacements using an improved digital correlation method. Image and Vision Computing 1983;1:133-9.

[88] Efstathiou C, Sehitoglu H, Lambros J. Multiscale strain measurements of plastically deforming polycrystalline titanium: Role of deformation heterogeneities. International Journal of Plasticity 2010;26:93. 